\title{
Comparison of exercise therapy and ultrasonic therapy in the treatment of shoulder impingement syndrome
}

\author{
Bhargava Shanker*1, D. Rajesh Reddy ${ }^{2}$, N.S.S.N. Balaji ${ }^{3}$. \\ ${ }^{* 1}$ Associate Professor, MNR Sanjeevani college of physiotherapy and MNR Hospital, Sangareddy, \\ Telangana, India.
}

2,3 Professor, MNR Sanjeevani college of physiotherapy and MNR Hospital, Sangareddy, Telangana, India.

\section{ABSTRACT}

Background: The shoulder is one of the most frequent sites of musculoskeletal pain, incidence of shoulder pain in primary care patients is estimated to be 11.2 per 1000 per year. a considerable number of people with shoulder pain (41\%) show persistent symptoms after 1 year. Comparing the exercise therapy and ultrasound therapy (UST) for impingement syndrome.

Methodology: The study was conducted at OPD of MNR Hospital in Sangareddy. The study was conducted for a period of 3 weeks. A total number of 30 subjects were selected by simple random sampling after explained to all the participants and an informed consent was taken from each subject. 30 subjects were randomly divided into 2 Groups. Exercise therapy was given to Group 1 and UST was given to Group 2. Both the Groups received exercise therapy and ultrasonic therapy in shoulder impingement syndrome. Subjects were evaluated pre and post treatment for VAS (Visual Analogue Scale) score, SPADI SCORE (Shoulder Pain and disability index) shoulder ROM.

Outcome measures: VAS scale, SPADI score.

Results and Discussion: To test the significance of the mean difference of two groups, unpaired t test was done. It is statistically shown that there is some significant impact in the parameters VAS, SPADI and shoulder ROM. The results showed that, group-I had more significant improvement in all parameters than group -II.

Conclusion: It is concluded that exercise therapy is better than ultrasonic therapy for subjects with shoulder impingement syndrome.

KEY WORDS: Exercise Therapy, Ultrasonic Therapy, Shoulder Pain and disability index, Range of Motion.

Address for correspondence: Dr. Bhargava Shanker, PT., Associate Professor, MNR Sanjeevani college of physiotherapy and MNR Hospital, Sangareddy, Telangana, India.

E-Mail: bhargavchowdary.bk@gmail.com

\section{Quick Response code International Journal of Physiotherapy and Research} ISSN (E) 2321-1822 | ISSN (P) 2321-8975

https://www.ijmhr.org/ijpr.html

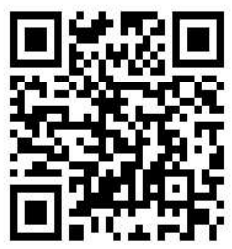

DOI: $10.16965 /$ ijpr.2021.121

DOI-Prefix: https://dx.doi.org/10.16965/ijpr

\section{Article Information}

Received: 04 Mar 2021

Peer Review: 05 Mar 2021

Revised: 08 Apr 2021
Accepted: 10 May 2021

Published (O): 11 Jun 2021

Published (P): 11 Jun 2021
INTRODUCTION

Shoulder pain is a common presenting complaint from patients of all ages in daily clinical practice, affecting approximately one-third of individuals during their lifetime. Such pain may lead to the impairment of shoulder joint function and to severe reduction in quality of life. Shoulder impingement syndrome, which is defined as the compression of the rotator cuff and the sub acromial bursa, is considered to be one of the most common causes of shoulder pain and may be cited as a contributing factor to shoulder pain in up to $65 \%$ of cases [1]. The shoulder is one of the most frequent sites of musculoskeletal pain, exceeded only by back and knee pain the incidence of shoulder pain in primary care patients is estimated to be 
11.2 per 1000 per year [2]. The course varies, but a considerable number of people with shoulder pain (41\%) show persistent symptoms after 1 year [3]. Many people with shoulder pain have signs of sub acromial impingement, which is characterised by pain and disability, mainly in activities above shoulder height. Sub acromial impingement is reported in 30 to $86 \%$ of shoulder pain patients in primary care, and $36 \%$ in secondary care [2]. Swimmer's shoulder is the term used to describe the problem of shoulder pain in the competitive swimmer. Swimming is an unusual sport in that the shoulders and upper extremities are used for locomotion, while at the same time requiring above average shoulder flexibility and range of motion (ROM) for maximal efficiency. This is often associated with an undesirable increase in joint laxity. Furthermore, it is performed in a fluid medium, which offers more resistance to movement than air. This combination of unnatural demands can lead to a spectrum of overuse injuries seen in the swimmer's shoulder, the most common of which is rotator cuff tendinitis [3].

The shoulder joint has the greatest range of motion of any joint in the body. Because of this mobility the shoulder is more likely to be injured or cause problems. They include sprains, strains, dislocations, separations, tendinitis, bursitis, torn rotator cuffs, frozen shoulder, fractures and arthritis. Among these conditions shoulder impingement syndrome is the most disabling condition of the shoulder [4].

Shoulder impingement syndrome, also called sub acromial impingement, painful arc syndrome, supraspinatus syndrome, swimmer's shoulder, and thrower's shoulder, is a clinical syndrome which occurs when the tendons of the rotator cuff muscles become irritated and inflamed as they pass through the sub acromial space, the passage beneath the acromion. This can result in pain, weakness and loss of movement at the shoulder. Physiotherapy is often the first choice of treatment for shoulder impingement syndrome. Between 10 to $30 \%$ of all shoulder patients seen in primary care are referred to physiotherapy after initial presentation, Physiotherapy is widely used in the management of shoulder impingement syndrome which includes various treatment methods such as shoulder exercises, manual therapy, and electrotherapy. Physiotherapy has been found to be effective in reducing pain and disability in patients with shoulder impingement [5-8]. The most common cause of shoulder pain in the older population is soft tissue injuries. These include frozen shoulder, sub acromial impingement, rotator cuff tendinopathy or rupture, arthritic conditions, degeneration and, or destruction of the joint and referred pain from cervical radiculopathy [4]. This condition is used in our study as majority of sub acromial impingement may be successfully managed with conservative treatment [6]. Specific supervised exercises obtain improvements in the range of movement and muscular function by restoring the shoulder's mobility and stability. Physiotherapeutic options include several electrotherapy techniques. Among them Ultrasound (US) Therapy is more popular [9-17].

In spite of the limited evidence to prove the effectiveness of ultrasonic therapy in the treatment of shoulder impingement syndrome it is a widely used electrotherapeutic modality to treat patients with soft tissue injuries including shoulder impingement syndrome [18-20]. Based on this our study was designed to assess whether ultrasonic therapy helps in rehabilitation of shoulder impingement syndrome in the acute and sub-acute stages.

Ultrasound is a commonly used electrotherapeutic modality for impingement as well as other forms of tendinitis and muscle injury. Therapeutic ultrasound is a modality commonly used by physiotherapist. Ultrasound therapy works by driving alternating compression and rarefaction of sound waves with a frequency of more than 20,000 cycles per seconds [21]. Therapeutic ultrasound may have two types of benefits, namely thermal effects and non-thermal effects [21-24].

Thermal effects aid in pain relief whereas non-thermal effects enhance cell-repair effects of the inflammatory response ${ }^{(7)}$ Reduction in 
pain and induce tissue repair helps in regaining the reduce range of motion due to shoulder impingement syndrome [25-27].

When recovering from a shoulder injury physiotherapy exercises are an integral part in regaining the range of motion, muscle elasticity, and strength [29-34]. Therapeutic exercises can be defined as the use of active or assisted exercises aimed at improving the range of motion, strength or dynamic neuromuscular control of joint motion [28-30], whereas manual therapy can be defined as the use of manually and/or mechanically applied movement techniques to improve joint motion [8].

\section{METHODOLOGY}

Study design: The experimental study was conducted in the form of pre-test, post-test with two interventional groups.

Sample collection: Simple Randomized sampling.

Study setting: The study was conducted at physiotherapy outpatient department of MNR Hospital in Sangareddy, medak dist.

Study sampling: A total number of 30 subjects was selected by simple random sampling after explained to all the participants and an informed consent was taken from each subject.

Group A - reducing pain, increasing joint ROM and strength of the joint and capsular Stretch with exercise therapy.

Group B - reducing pain, increasing joint ROM with ultrasonic therapy

Study Duration: One year.

\section{Criteria for selection:}

Inclusion criteria: Subjects with Age between 18 and 55 year, Both genders, Diagnosed cases of shoulder impingement syndrome with a duration of more than 3 weeks, Main complaints in the glenohumeral joint region or the proximal arm. Shoulder pain resistant to antiinflammatory drugs. A positive clinical neer's test.

Exclusion criteria: Patients who have undergone total shoulder arthroplasty, Neoplastic conditions, Psychiatric disorders, Patients with rheumatoid arthritis, Adhesive capsulitis (frozen shoulder), Substantial shoulder weakness or loss of active shoulder function, Diabetic patients.

Materials used in the study: Chair, SPADI scale, Universal goniometer, VAS scale, Ultra-sound, Shoulder overhead rope pulley, Hand cuffed weights, Therapeutic gel, Ice packs, Treatment table

Procedure: The study was done on 30 patients and the subjects were randomly placed in to 2 groups, 15 in each group. The total duration was taken for 3 weeks. Patients in both the groups were assesses for the following parameters before starting the treatment. Range of motion using goniometer. Functional deficit by using SPADI. Pain measurement using VAS (intensity)

Group A: A protocol for group A sample of the 15 participants involved the application of shoulder exercises for a total of 15 treatment sessions of 40 minutes, over a period of 3 consecutive weeks ( 5 days per week).

The treatments in the first week aimed at reducing the pain intensity and to prevent further damage and consisted of free exercises of shoulder and transverse friction massage and shoulder pendulum exercises.

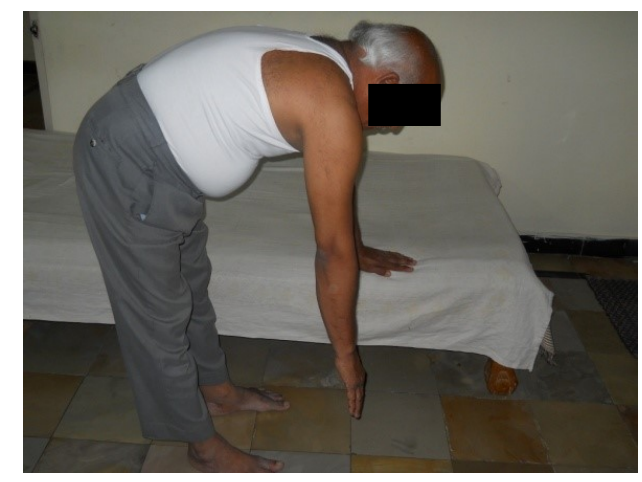

Fig. 1: Shoulder pendulum exercises

The second and third week aimed at restoring the functional level by increasing ROM, muscle strength and flexibility and consisted of ROM exercises with rope and pulley, L bar exercises, self-capsular stretching exercises, and strengthening exercises with weights, therapeutic bands, springs and push ups. The standard exercise protocol were given in order to restore muscular deficits in strength, mobility, and coordination of the rotator cuff and the shoulder girdle muscles to unload the 
subacromial space during active movements. And the participants were expected to return to their functional level without recurrence at the end of the treatment.

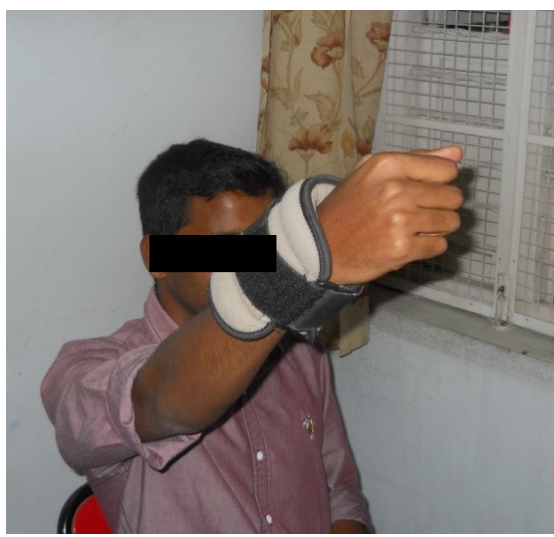

Fig. 2: Shoulder strengthening exercises

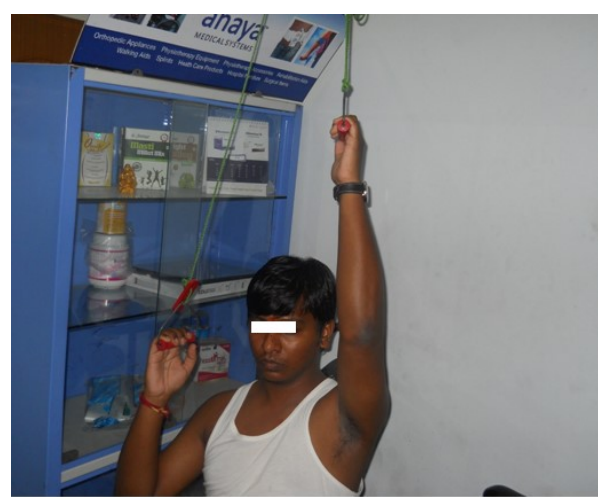

Fig. 3: Abduction and flexion exercises with rope and pulley.

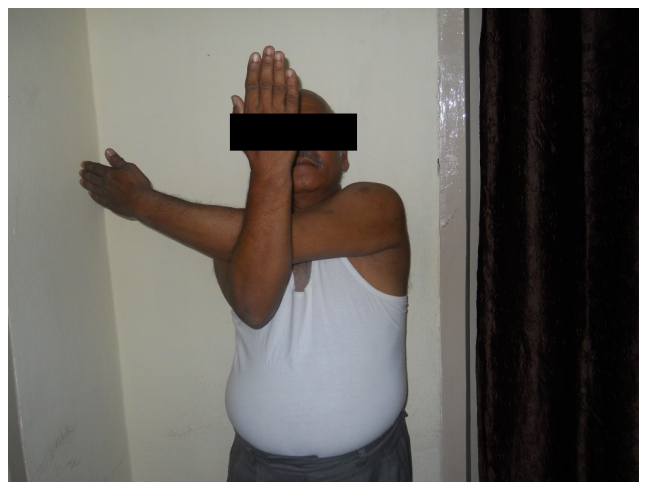

Fig. 4: Shoulder capsular stretching exercises.

Group B: Participants in the intervention group received pulsed ultrasound for 10 minutes with a device that was operated at a frequency of $1 \mathrm{MHz}$, and an intensity of $1 \mathrm{~W} / \mathrm{cm}^{2}$, The treating physical therapist, using the technique of slow circular movements, applied the transducer head over the superior and anterior periarticular regions of the participant's glenohumeral joint and on the shoulder trigger points. The treatment was continued a period of 3 consecutive weeks (5 days per week).

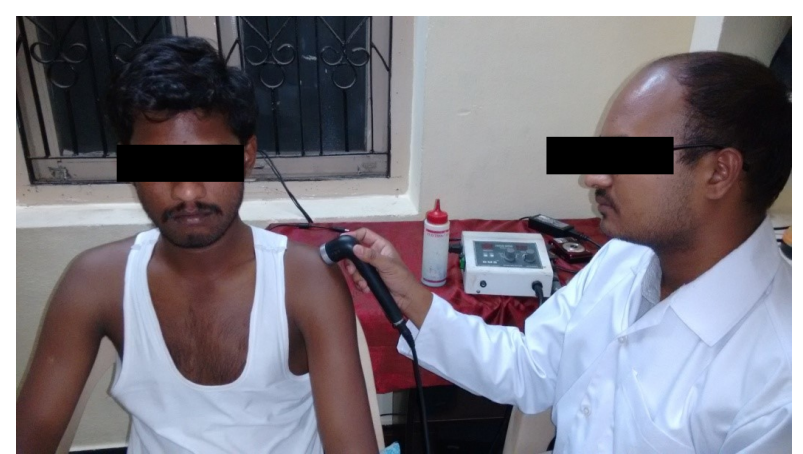

Fig 5: The participant being treated with Ultrasound therapy.

Procedure: All shoulder ROMs were measured using the universal goniometer. Shoulder flexion, abduction, and external rotation were measured in the supine position whereas shoulder extension and external rotation were measured in the prone position. The axis of goniometer was placed at $2.5 \mathrm{~cm}$ inferior to the lateral aspect of the acromion process for shoulder flexion and extension, at $1.3 \mathrm{~cm}$ inferior and lateral to the coracoid process for abduction and at the olecranon process of the ulna for shoulder internal and external rotation.

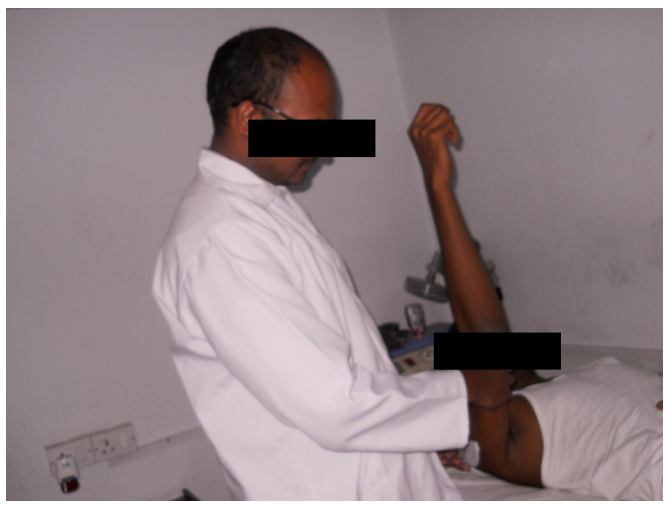

Fig. 6: Goniometric measurement of shoulder ROM

\section{RESULTS}

The data collected and subjected to statistical analysis supports the hypothesis that both exercise therapy and ultrasonic therapy are effective on reducing pain and improving the function in patients with shoulder impingement syndrome.

Further analysis also supports the hypothesis that there is a significant difference in the effectiveness of both exercise therapy and ultrasonic therapy in shoulder impingement syndrome.

The study proves that both can be preferred for treatment of shoulder impingement 
syndrome patients but exercise therapy technique is more effective than ultrasonic therapy in reducing pain and improving function.

A sample of 30 subjects were selected for the study of comparison of exercise therapy and ultrasonic therapy in shoulder impingement syndrome.

VAS: Group Statistics.

Table1: This table is calculating the N, Mean, Standard Deviation, Minimum and maximum values for VAS

\begin{tabular}{cccccc}
\hline & Group & N & Mean & $\begin{array}{c}\text { Std. } \\
\text { Deviation }\end{array}$ & $\begin{array}{c}\text { Std. Error } \\
\text { Mean }\end{array}$ \\
\hline \multirow{2}{*}{ Pre } & Group A & 15 & 7.9333 & 0.79881 & 0.20625 \\
& Group B & 15 & 8.0667 & 0.88372 & 0.22817 \\
\multirow{2}{*}{ Post } & Group A & 15 & 2.6 & 0.91026 & 0.23503 \\
& Group B & 15 & 1.9333 & 0.79881 & 0.20625 \\
\hline
\end{tabular}

\begin{tabular}{cc} 
Series1, Pre & Series1, Pre \\
Group A, 7.93 & Group B, 8.07 \\
\hline
\end{tabular}

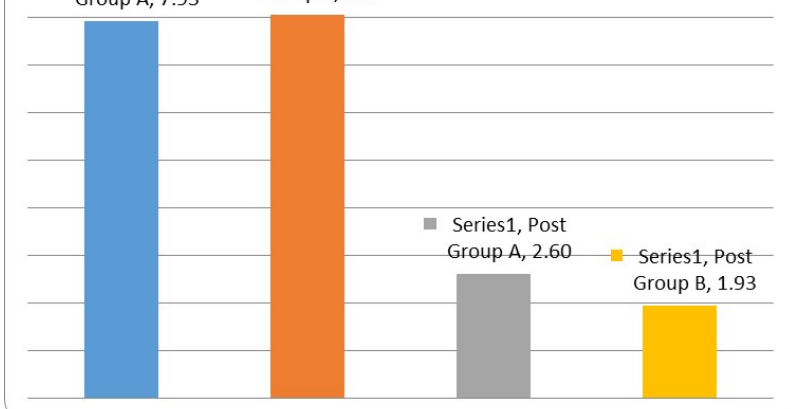

Graph1

\section{Mann-Whitney Test:}

\section{Ranks}

\begin{tabular}{ccccc}
\hline & Group & N & $\begin{array}{c}\text { Mean } \\
\text { Rank }\end{array}$ & $\begin{array}{c}\text { Sum of } \\
\text { Ranks }\end{array}$ \\
\hline \multirow{4}{*}{ Pre } & Group A & 15 & 14.83 & 222.5 \\
& Group B & 15 & 16.17 & 242.5 \\
& Total & 30 & & \\
& Group A & 15 & 18.53 & 278 \\
Post & Group B & 15 & 12.47 & 187 \\
& Total & 30 & & \\
\hline
\end{tabular}

\section{Test Statistics ${ }^{b}$}

\begin{tabular}{lcc}
\hline & Pre & Post \\
\hline Mann-Whitney U & 102.5 & 67 \\
Wilcoxon W & 222.5 & 187 \\
\hline Z & -0.44 & -1.987 \\
Asymp. Sig. (2-tailed) & 0.66 & 0.047 \\
Exact Sig. [2*(1-tailed Sig.)] & $.683^{\mathrm{a}}$ & $.061^{\mathrm{a}}$ \\
\hline
\end{tabular}

Table 2: a. Not corrected for ties.

b. Grouping Variable: Group

As can be seen from the output, not significant difference exists between Group $A$ and Group B Vas Pre Since Z-value is -0.440 and its p-value 0.660 is Greater than 0.05 .
As can be seen from the output, a significant difference exists between Group A and Group $B$ Vas Post Since Z-value is -1.987 and its p-value 0.047 is less than 0.05 .

\section{SPADI}

Table 3: This table is calculating the $\mathrm{N}$, Mean, Standard Deviation, Minimum and maximum values for SPADI

Group Statistics

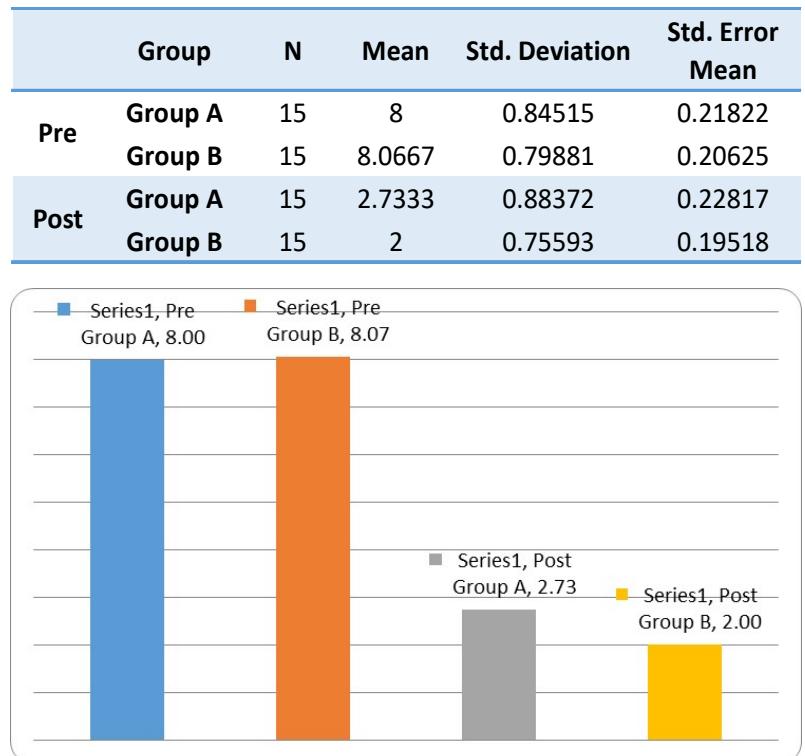

Graph2

\section{Mann-Whitney Test}

Ranks

\begin{tabular}{ccccc}
\hline & Group & N & Mean Rank & Sum of Ranks \\
\hline \multirow{4}{*}{ Pre } & Group A & 15 & 15.17 & 227.5 \\
& Group B & 15 & 15.83 & 237.5 \\
& Total & 30 & & \\
\multirow{4}{*}{ Post } & Group A & 15 & 18.83 & 282.5 \\
& Group B & 15 & 12.17 & 182.5 \\
& Total & 30 & & \\
\hline
\end{tabular}

Test Statistics ${ }^{b}$

\begin{tabular}{ccc}
\hline & Pre & Post \\
\hline Mann-Whitney U & 107.5 & 62.5 \\
\hline Wilcoxon W & 227.5 & 182.5 \\
\hline Z & -0.22 & -2.193 \\
\hline Asymp. Sig. (2-tailed) & 0.826 & 0.028 \\
\hline Exact Sig. [2*(1-tailed Sig.)] & $.838^{\text {a }}$ & $.037^{\text {a }}$ \\
\hline
\end{tabular}

Table 3: Not corrected for ties.

b. Grouping Variable: Group

As can be seen from the output, not significant difference exists between Group $A$ and Group B SPADI Pre Since Z-value is -0.220 and its $p$-value 0.826 is Greater than 0.05 .

As can be seen from the output, a significant difference exists between Group A and Group B SPADI Post Since Z-value is -2.193 and its 
p-value 0.028 is Greater than 0.05 .

\section{ACTIVE ROM}

Group Statistics

\begin{tabular}{cccccc}
\hline & Group & N & Mean & $\begin{array}{c}\text { Std. } \\
\text { Deviation }\end{array}$ & $\begin{array}{c}\text { Std. Error } \\
\text { Mean }\end{array}$ \\
\hline \multirow{2}{*}{ Pre } & Group A & 15 & 114.3333 & 15.10282 & 3.89953 \\
& Group B & 15 & 117.3333 & 17.61358 & 4.54781 \\
\multirow{2}{*}{ Post } & Group A & 15 & 162.3333 & 9.6115 & 2.48168 \\
& Group B & 15 & 169.3333 & 12.08108 & 3.11932 \\
\hline
\end{tabular}

Table 4: This table is calculating the N, Mean, Standard Deviation, Standard error values for Active Rom.

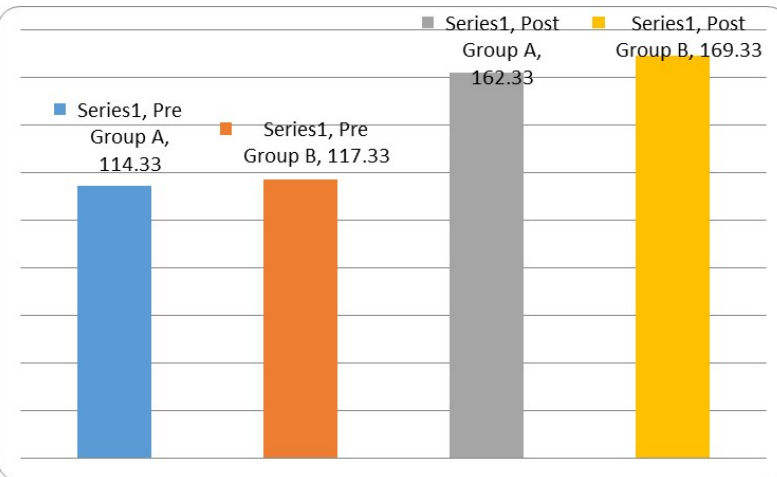

Table 5: As can be seen from the output, not significant difference exists between Group A and Group B Active Rom Pre Since t-value is -0.501 and its $p$-value 0.620 is Greater than 0.05 .

Independent Samples Test.

\begin{tabular}{ccccccc}
\hline & & \multicolumn{5}{c}{ t-test for Equality of Means } \\
\cline { 3 - 7 } & $\mathbf{t}$ & df & $\begin{array}{c}\text { Sig. } \\
\text { (2-tailed) }\end{array}$ & $\begin{array}{c}\text { Mean } \\
\text { Difference }\end{array}$ & $\begin{array}{c}\text { Std. Error } \\
\text { Difference }\end{array}$ \\
\hline Pre & $\begin{array}{c}\text { Equal variances } \\
\text { assumed }\end{array}$ & -0.501 & 28 & 0.62 & -3 & 5.99073 \\
Post & $\begin{array}{c}\text { Equal variances } \\
\text { assumed }\end{array}$ & -1.756 & 28 & 0.09 & -7 & 3.98609 \\
\hline
\end{tabular}

As can be seen from the output, a significant difference exists between Group A and Group B Active Rom Post Since Z-value is -1.756 and its $p$-value 0.09 is less than 0.10 .

\section{DISCUSSION}

In shoulder impingement syndrome patients exercise therapy techniques are effective treatment for reducing pain and improving function.

Imbalances or deficits in muscular strength and activation levels can lead to functional impingement. Both glenohumeral and scapulothoracic muscle imbalances can contribute to shoulder complex dysfunction.
The pathomechanics of functional impingement may involve one or both shoulder forcecouples, deltoid/rotator cuff and scapular rotators.

Most of the participants had been affected by their dominant shoulder. But some of them had been affected by their non -dominant shoulder. But according to the results comparison between baseline measurements and overall improvement has no significant difference in either group.

In the present study both the intervention groups have significant improvement after three weeks of treatment. There is significant improvement in pain reduction, disability, and shoulder ROM from baseline measurements to the first, second and third week after treatment in both the groups. The received shoulder exercises alone and these treatments have led to the significant improvement. These findings support the previous study results and emphasize the importance of manual therapy and shoulder exercises in the treatment of patients with shoulder impingement syndrome.

Therapeutic ultrasound may have two types of benefit: Thermal effects and non-thermal effects. Thermal effects aids in pain relief whereas non thermal effects enhance the cell-repair effects of the inflammatory response [7]. Reduction in pain and induced tissue repair are believed to help in regaining the reduced ROM due to shoulder impingement syndrome.

The present study also shows that there is no significant difference between the control group which received shoulder exercises and intervention group which received ultrasound therapy in addition. According to the present study results, ultrasound therapy does not have an additional effect when combined with shoulder exercise therapy.

The present study aimed not only at proving that ultrasound therapy does not have an added effect when combined with shoulder exercise therapy in relieving symptoms in patients with Shoulder impingement syndrome without the use of any electrotherapeutic modality.

The data collected and subjected to statistical analysis supports the hypothesis that both 
exercise therapy and ultrasonic therapy are effective on reducing pain and improving the function in patients with shoulder impingement syndrome.

Further analysis also supports the hypothesis that there is a significant difference in the effectiveness of both exercise therapy and ultrasonic therapy in shoulder impingement syndrome.

The study proves that both can be preferred for treatment of shoulder impingement syndrome patients, but exercise therapy technique is more effective than ultrasonic therapy in reducing pain and improving function.

A sample of 30 subjects were selected for the study of comparison of exercise therapy and ultrasonic therapy in shoulder impingement syndrome.

In shoulder impingement syndrome patients exercise therapy techniques are effective treatment for reducing pain and improving function.

Imbalances or deficits in muscular strength and activation levels can lead to functional impingement. Both glenohumeral and scapulothoracic muscle imbalances can contribute to shoulder complex dysfunction. The pathomechanics of functional impingement may involve one or both shoulder force couples: deltoid/rotator cuff and scapular rotators.

Most of the participants had been affected by their dominant shoulder. But some of them had been affected by their non -dominant shoulder. But according to the results comparison between baseline measurements and overall improvement has no significant difference in either group.

In the present study both the control and intervention groups have significant improvement after three weeks of treatment. There is significant improvement in pain reduction, disability, and shoulder ROM from baseline measurements to the first, second and third week after treatment in both the groups. The control group received shoulder exercises alone and these treatments have led to the significant improvement in the control group.
These findings support the previous study results and emphasize the importance of manual therapy and shoulder exercises in the treatment of patients with shoulder impingement syndrome.

Therapeutic ultrasound may have two types of benefit: Thermal effects and non-thermal effects. Thermal effects aids in pain relief whereas non thermal effects enhance the cell-repair effects of the inflammatory response. Reduction in pain and induced tissue repair are believed to help in regaining the reduced ROM due to shoulder impingement syndrome.

The present study also shows that there is no significant difference between the control group which received shoulder exercises and intervention group which received ultrasound therapy in addition. According to the present study results, ultrasound therapy does not have an additional effect when combined with shoulder exercise therapy.

The present study aimed not only at proving that ultrasound therapy does not have an added effect when combined with shoulder exercise therapy in relieving symptoms in patients with Shoulder impingement syndrome without the use of any electrotherapeutic modality.

Limitation of the study: Sample Size limited to 30 , There was no long term follow up of the patients after the study.

Suggestions for future study: The Same Techniques can be applied for a longer duration for 4 weeks also.

\section{CONCLUSION}

The study finally concludes that exercise therapy is more effective than ultrasonic therapy in reducing, disability and pain, increasing and improving function and ROM of shoulder in shoulder impingement syndrome. Ultrasound therapy has no additional benefit when combined with shoulder exercises in the treatment of patients with shoulder impingement syndrome.

\section{ACKNOWLEDGEMENTS}

We are grateful to all the participants for providing time for the study. A heartfelt gratitude 
to the Management of MNR's Sanjeevani College of Physiotherapy, Sangareddy for providing infrastructure and facilities to carry out the study.

\section{ABBREVATIONS}

VAS - Visual Analogue Scale

SPADI - Shoulder Pain and disability index

ROM - Range of Motion

\section{Conflicts of interest: None}

\section{REFERENCES}

[1]. Dong W, Goost H, Lin XB, Burger C, Paul C, Wang ZL, Zhang TY, Jiang ZC, Welle K, Kabir K. Treatments for shoulder impingement syndrome: a PRISMA systematic review and network meta-analysis. Medicine (Baltimore). 2015 Mar;94(10):e510.

[2]. García I, Lobo C, López E, Serván JL, Tenías JM. Comparative effectiveness of ultrasonophoresis and iontophoresis in impingement syndrome: a doubleblind, randomized, placebo controlled trial. Clin Rehabil. 2016 Apr;30(4):347-58.

[3]. Granviken F, Vasseljen O. Home exercises and supervised exercises are similarly effective for people with subacromial impingement: a randomised trialJ Physiother. 2015 Jul;61(3):135-41.

[4]. Moezy A, Sepehrifar S, Solaymani Dodaran M. The effects of scapular stabilization based exercise therapy on pain, posture, flexibility and shoulder mobility in patients with shoulder impingement syndrome: a controlled randomized clinical trial. Med J Islam Repub Iran. 2014 Aug 27;28:87.

[5]. Calis HT, Berberoglu N, Calis M. Are ultrasound, laser and exercise superior to each other in the treatment of subacromial impingement syndrome? A randomized clinical trial. Eur J Phys Rehabil Med. 2011 Sep;47(3):375-80.

[6]. Zhou Z., Salle J. Y., Daviet J. C., Stuit A., Nguyen C. L. Combined approach in bedside assessment of aspiration risk post stroke: PASS. European Journal of Physical and Rehabilitation Medicine 2011 September;47(3):441-6

[7]. Angela R. Tate, Philip W. McClure, Ian A. Young, Renata Salvatori, Lori A. Michener, Comprehensive Impairment-Based Exercise and Manual Therapy Intervention for Patients With Subacromial Impingement Syndrome: A Case Series journal of orthopaedic \& sports physical therapy 2010;40(8):47493.

[8]. Celik, D., Atalar, A.C., Sahinkaya, S., Demirhan, M. The value of intermittent ultrasound treatment in subacromial impingement syndrome. Acta Orthop Traumatol Turc. 2009;43(3):243-7.

[9]. McClure P, Balaicuis J, Heiland D, Broersma ME, Thorndike CK, Wood A. A randomized controlled comparison of stretching procedures for posterior shoulder tightness. journal of orthopaedic \& sports physical therapy. 2007 Mar;37(3):108-14.
[10]. MacDermid JC, Solomon P, Prkachin K. The Shoulder Pain and Disability Index demonstrates factor, construct and longitudinal validity. BMC musculoskeletal disorders. 2006 Dec;7(1):1-1.

[11]. Kurtai., Gürsel, Y., Ulus, Y., Bilgiç, A., Dinçer, G., van der Heijden, G.J. Adding Ultrasound in the management of soft tissue disorders of the shoulder: a Randomized placebo-controlled trial. Phys Ther. 2004;84(4):336-43.

[12]. Bang, M.D., Deyle, G.D. Comparison of supervised exercise with and without manual physical therapy for patients with shoulder impingement syndrome. J Orthop Sports PhysTher, 2000;30:126-137.

[13]. Heald SL, Riddle DL, Lamb RL. The shoulder pain and disability index: the construct validity and responsiveness of a region-specific disability measure. Phys Ther. 1997 Oct;77(10):1079-89.

[14]. Game AN, Johannsen F. Ultrasound therapy in musculoskeletal disorders: a meta-analysis. Pain. 1995 Oct;63(1):85-91.

[15]. Pribicevic, M., Pollard, H., Bonello, R., De Luca, K., 2010. A systematic review of manipulative therapy for the treatment of shoulder pain, Manipulative PhysiolTher, 2010;33(9):679-89.

[16]. Purdy, S., Williams, J.R. A comparison of functional, patient-based scores in subacromial impingement. Journal of Shoulder and Elbow Surgery, 2005;14:380-384.

[17]. Brotzman, S.B., Wilk, K.E., 2003. Clinical orthopedic rehabilitation, $2^{\text {nd }}$ ed., United Kingdom-Mosby.

[18]. Roy, J.S.,Moffet, H., Hebert, L.J., Lirrette, R. Effect of motor control and strengthening exercises on shoulder function in persons with impingement syndrome: A single-subject study design, Manual therapy, 2007;14:180-188.

[19].Santamato, A., Solfrizzi, V., Panza, F., Tond, G., Frisardi, V., Leggin, B.G., Ranieri, M., Fiore, P. Shortterm effects of high-intensity laser therapy versus ultrasound therapy in the treatment of people with subacromial impingement syndrome: a randomized clinical trial. PhysTher, 2009;89(7):643-52.

[20]. Somty, R., 2002. OMT: what is it? International Federation of Orthopaedic Manipulative Therapists Web site [Online] Available at: http:// www.omt.org/homepage/omt/omt.html. [Accessed October 2002.]

[21]. Szyluk, K., Jasiñski, A., Koczy, B., Widuchowski, W., Widuchowski, J. Subacromial impingement syndrome-most frequent reason of the painful shoulder syndrome. Pol Merkur Lekarski. 2008;25(146):179-83.

[22]. Valma, J., Robertson, Kerry, G., Baker. A Review of Therapeutic Ultrasound: Effectiveness Studies, Physical Therapy. 2001;81(7):1339-1350.

[23]. Williamson, M.P., Chandnani, V.P., Baird, D.E., Reeves, T.Q., Deberardino, T.M., Swenson, G.W., Hansen, M.F. Shoulder impingement syndrome: diagnostic accuracy of magnetic resonance imaging and radiographic signs. Australas Radiol. 1994;38(4):265-71. 
[24]. Green S, Buchbinder R, Hetrick S. Physiotherapy interventions for shoulder pain. Cochrane Database Syst Rev. 2003. CD004258. DOI: 10.1002/ 14651858.

[25]. Lewis J, Green A, Wright C. Subacromial impingement syndrome: the role of posture and muscle imbalance. Journal of Shoulder and Elbow Surgery. 2005;14(4):385 92.

[26]. Hsu Y, Chen W, Lin H., et al. The effects of taping on scapular kinematics and muscle performance in baseball players with shoulder impingement syndrome. J Electromyogr Kinesiol. 2009;19(6): 10921099.

[27]. Miller P, Osmotherly P. Does scapula taping facilitate recovery for shoulder impingement symptoms? A pilot Randomized Controlled Trial. J Man Manipulative Ther. 2009; 17(1):E6 E13.

[28]. Pappas GP, Blemker SS, Beaulieu CF., et al. In vivo anatomy of the Neer and Hawkins sign positions for shoulder impingement. J Shoulder Elbow Surg. 2006; 15:40 49.

[29]. Koester MC, George MS, Kuhn JE. Shoulder impingement syndrome" 2015;118(5).

[30]. Lewis JS. Rotator cuff tendinopathy/subacromial impingement syndrome: is it time for a new method of assessment?. British journal of sports medicine. 2009 Apr 1;43(4):259-64.

[31]. Fongemie AE, Buss DD, Rolnick SJ. Management of shoulder impingement syndrome and rotator cuff tears. American family physician. 1998 Feb $15 ; 57(4): 667$.

[32]. Neer 2nd CS, Foster CR. Inferior capsular shift for involuntary inferior and multidirectional instability of the shoulder. A preliminary report. JBJS. 1980 Sep 1;62(6):897-908.

[33]. Oh JH, Kim SH, Kim KH, Oh CH, Gong HS. Modified impingement test can predict the level of pain reduction after rotator cuff repair. The American journal of sports medicine. $2010 \mathrm{Jul} ; 38(7): 1383-8$.

[34]. Arend CF. Ultrasound of the Shoulder. Master Medical Books, 2013

[35]. Santamato A, Solfrizzi V, Panza F, et al. Randomized clinical trial people with subacromial impingement syndrome: a versus ultrasound therapy in the treatment of short-term effects of high-intensity laser therapy.Phys Ther, 2009;89:643-652.
[36]. Husni EM, Donohue JP.: Painful Shoulder and Reflex Sympathetic Dystrophy Syndrome. Arthritis and Allied Conditions, 15th ed. Philadelphia: Lippincott Williams Wilkins, 2005.

[37]. Robertson VJ, Baker KG.: A review of therapeutic ultrasound: effectiveness studies. Phys Ther, 2001;81:1339-1350.

[38]. Ebenbichler GR, Erdogmus CB, Resch KL, Funovics $M A$, Kainberger F, Barisani $G$, Aringer $M$, Nicolakis $P$, Wiesinger GF, Baghestanian M, Preisinger E. Ultrasound therapy for calcific tendinitis of the shoulder. New England Journal of Medicine. 1999 May 20;340(20):1533-8.

[39]. Johansson KM, Adolfsson LE, Foldevi MO. Effects of acupuncture versus ultrasound in patients with impingement syndrome: randomized clinical trial. Physical therapy. 2005 Jun 1;85(6):490-501.

[40]. Danicella AWM, Geert JMG. Ultrasound therapy for musculoskeletal disorders, a systematic review. Pain 1999;81:251-271.

[41]. Gursel YK, Ulus Y, Bilgic A, Dincer G, van der Heijden GJ. Adding ultrasound in the management of soft tissue disorders of the shoulder: a randomized placebo-controlled trial. Physical therapy. $2004 \mathrm{Apr}$ 1;84(4):336-43.

\footnotetext{
How to cite this article:

Bhargava Shanker, D. Rajesh Reddy, N.S.S.N. Balaji. Comparison of exercise therapy and ultrasonic therapy in the treatment of shoulder impingement syndrome. Int J Physiother Res 2021;9(3):3825-3833. DOI: 10.16965/ ijpr.2021.121
} 